\title{
Preparation and Property Analysis of Melamine Formaldehyde Foam
}

\author{
Dongwei Wang, Xiaoxian Zhang, Song Luo, Sai Li \\ School of Chemical Engineering, Sichuan University, Chengdu, China \\ Email: wangdongwei820920@126.com, lisai@scu.edu.cn
}

Received 2012

\begin{abstract}
Melamine formaldehyde (MF) foam is kind of fire-retardant material and has great potential in acoustic and thermal insulation area. In this article, MF resin foam was prepared by microwave radiation. We discussed the thermal stability of MF foam and the effect of different emulsifiers on its morphology, apparent density, fire-retardancy and mechanical property. The decomposition temperature of MF foam we prepared is nearly $400^{\circ} \mathrm{C}$ and the constitution of residue after combustion is made up of carbon and graphite. Emulsifier influenced the apparent density of MF foam and using coemulsifiers can get flexible foam with uniform cell size, good morphology and low apparent density. When the fire-retardant MF foam's apparent density is low of $5.53 \mathrm{~kg} / \mathrm{cm}^{-3}$, its value of LOI can reach 32.4. The mechanical property of foam is consistent with apparent density.
\end{abstract}

Keywords: Melamine Formaldehyde Resin; Foam; Emulsifier; Morphology

\section{Introduction}

MF foam is a kind of thermosetting plastic and has attracted much attention all over the world. Because of its properties as the low density, corrosion resisting, good autologous fire-retardancy and high thermal stability it can be used for a long time in the environment of temperature as high as $150^{\circ} \mathrm{C}$ [1]. Up to now, only several companies including BASF, Illtec and Zhong Yuan Da Hua CO. can produce flexible MF foam [2]. This kind of MF foam has a skeleton of length/diameter (L/D) to 15 or even higher and can be practically used in acoustic area [3-4] due to its three-dimensional network structure and high cell-opening ratio. Many researchers have done lots of researches to solve its rigidity problem. For example, glycerol [5], isocyanate [6] as well as substituted melamine [7] had been added into MF resin to improve its flexibility. As we all know, emulsifier can reduce the interfacial tension and increase the contact area between foaming agent and MF resin which is benefit to foaming. But different kinds of emulsifiers had different fields of application and apparent density caused by emulsifiers will affect the fire-retardancy and mechanical property. The corresponding basic research on foaming happens of MF foam with different emulsifiers has not been seen in recent papers. In this paper, we discussed the cell morphology with different emulsifiers under the radiation of microwave and apparent density, fire-retardancy and mechanical property caused by emulsifiers. These experimental results will provide significant theoretical foundation for producing superior MF foam.

\section{Experiment}

\subsection{Materials}

Melamine (99\%), formaldehyde( $37 \%$ ), $\mathrm{NaOH}$, petroleum ether $\left(30 \sim 60{ }^{\circ} \mathrm{C}\right)$, dimethyl silicone oil (H-201), tween-80, Octyl phenol ethoxylates (OP-10) and sodium dodecylbenzenesulfonate (SDBS), acetic acid and so on are analytically pure, they are all purchased from KeLong Reagent Corporation Chengdu.

\subsection{Preparation of MF Foam}

Melamine and $37 \%$ formaldehyde with the molar ratio of $1: 3$ were added to flask with three necks equipped with motor stirrer, thermometer and condenser and heated to about $60^{\circ} \mathrm{C}$ and kept for a few minutes until the solution became clear. Then $10 \% \mathrm{NaOH}$ was dripped to adjust the $\mathrm{pH}$ of the solution to 8.5 , and emulsifier can be added with the mass ratio $2 \%$ of the resin. And then the solution was kept to the temperature of about 85 ${ }^{\circ} \mathrm{C}$ for properly $2 \sim 3 \mathrm{~h}$ till the viscosity of the system up to 2000 $\mathrm{cm} \cdot \mathrm{Pa}$ and cooled to room temperature and MF resin was obtained. Took a certain amount of MF resin and about 3\% acetic acid and $10 \%$ petroleum ether the mass ratio of the MF resin together were added and agitated vigorously to uniform and put into the microwave oven to foam without restraint of volume for about $5 \mathrm{~min}$. Finally the MF foam was put into air oven at $120^{\circ} \mathrm{C}$ to wipe off water, residual formaldehyde and for further cross-linking to transfer ether bond to methylene [8].

\subsection{Test and Analysis}

Fourier transform Infrared (FTIR) spectra were measured in the spectral range from 400 to $4000 \mathrm{~cm}^{-1}$, on a Nicollet $380 \mathrm{FT}$-IR, $\mathrm{KBr}$ tablet, Thermo Electron Corporation spectrometer, USA. Thermo gravimetric analysis (TG) was carried out with a Setaram Setsys TG-DTA, samples were heated from room temperature to $700^{\circ} \mathrm{C}$ in a $50 \mathrm{ml} / \mathrm{min}$ flow of $\mathrm{N}_{2}$ and heating rates of $10^{\circ} \mathrm{C} / \mathrm{min}$. Differential Scanning Calorimeter, DSC, GRN1CDR-4P system, samples were heated from room temperature to $360^{\circ} \mathrm{C}$ in a $50 \mathrm{ml} / \mathrm{min}$ flow of $\mathrm{N}_{2}$ and heating rates of $10^{\circ} \mathrm{C}$ 
/min. Field Emission Scanning Electron Microscopy (FE-SEM, JEOL, JSM-6700F) to evaluate the morphology of the samples. The Limited Oxygen Index (LOI) test was performed according to the testing procedure of the ASTMD-2836 Oxygen Index Method. X-ray Diffraction, XPert Pro MPD, Philips, Netherlands, $5^{\circ} \leq 2 \theta \leq 50^{\circ}$. Mechanics of compression test by universal testing machine at the rate of $5.0 \mathrm{~mm} / \mathrm{min}$ until the deformation up to $70 \%$, Instron 3360 series and RHW-50A system.

\section{Results and Discussion}

\subsection{FTIR Spectrum Analysis}

The cross-linking in acid solution of methylolmelamines can only form methylene [9]. However, two kinds of structure i.e. the methylene and ether bond should be both existed theoretically according to Figure 1.

The FTIR spectrum of pristine melamine and MF resin foam without aging as well as MF foam aging $2 \mathrm{~h}$ in $120^{\circ} \mathrm{C}$ are shown in Figure 2. In the melamine IR spectrum, $3415 \mathrm{~cm}^{-1}, 3123 \mathrm{~cm}^{-1}$, $3476 \mathrm{~cm}^{-1}, 3336 \mathrm{~cm}^{-1}$ represent the characteristic absorption peak of primary amine respectively, $1645 \mathrm{~cm}^{-1}, 1535 \mathrm{~cm}^{-1}$ are attributed to the absorption peak of triazinyl. It is apparent that the peak of $813 \mathrm{~cm}^{-1}$ exists in all these three IR spectrums which is the characteristic peak of triazinyl [10]. Correspondingly, in the IR spectrum of MF resin foam without aging and MF foam aging $2 \mathrm{~h}$ in $120^{\circ} \mathrm{C}$, it appears a new peak at $3440 \mathrm{~cm}^{-1}$, which represents the stretching vibration of $\mathrm{O}-\mathrm{H}$ and $\mathrm{N}-\mathrm{H}$ band with the peak of primary amine disappeared. These bands confirmed that melamine and formaldehyde are successfully cross-linked. The band of $2941 \mathrm{~cm}^{-1}$ is corresponding to the stretching vibration of C-H. And the new peak at about $1320 \mathrm{~cm}^{-1}$ represents the vibration of methane. Especially, in the curve of MF foam without aging, $1079 \mathrm{~cm}^{-1}$ showed that the structure of $\mathrm{C}-\mathrm{O}-\mathrm{C}$ is formed and after aging this peak disappeared which confirmed the theoretical prediction.

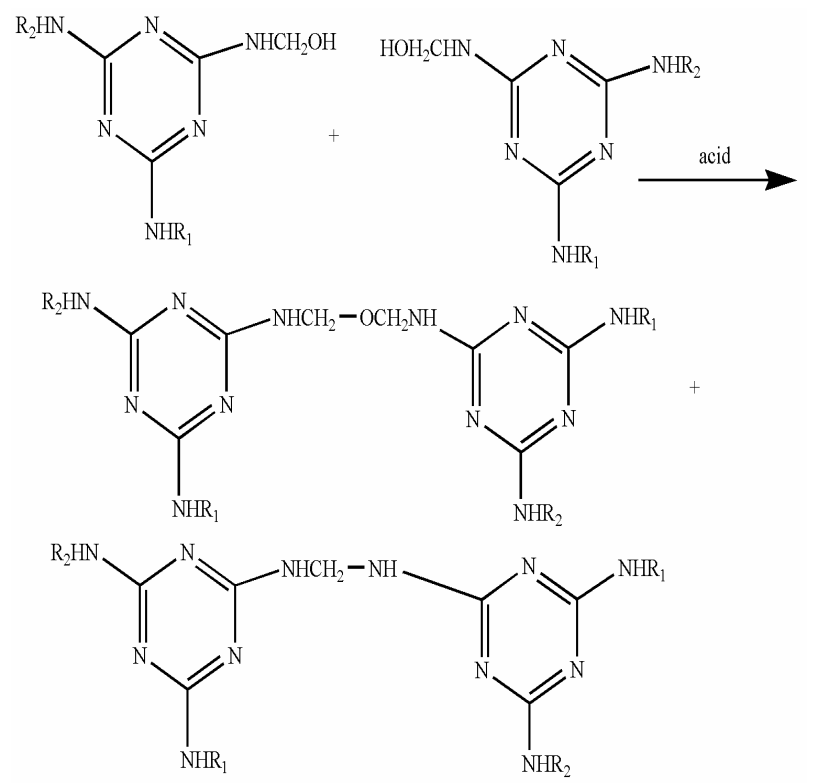

Figure 1. The proper cross-linking ways of methylolmelamines in acid circumstances.

\subsection{Thermal Stability of MF Foam}

Figure 3 is the TG curve of MF foam. Its decomposition temperature is nearly $400^{\circ} \mathrm{C}$. During the weight loss from room temperature to $350^{\circ} \mathrm{C}$ a series of small molecules including the residual water, foaming agent, emulsifier, formaldehyde and partly MF molecule with structural defects evaporated. These molecule structural defects are caused by the rapid cross-linking reaction when foamed by microwave radiation. Even when temperature is as high as $700^{\circ} \mathrm{C}$ the residue still reserves about $20 \%$ of original weight.

Figure 4 is the DSC curve of MF foam. The sample was heated to the temperature of $360^{\circ} \mathrm{C}$ which did not reach the decomposition temperature. There are just two endothermic peaks appeared in the DSC curve of MF foam. One small peak is at $150^{\circ} \mathrm{C}$ and a relative sharp and larger peak at $184^{\circ} \mathrm{C}$, but it is different to the result given by Jiang [11]. We attributed the two peaks to the fact that part of the methylolmelamines did not participate in the process of cross-linking and the cross-linking reaction is not fully enough. As a consequence, in the process

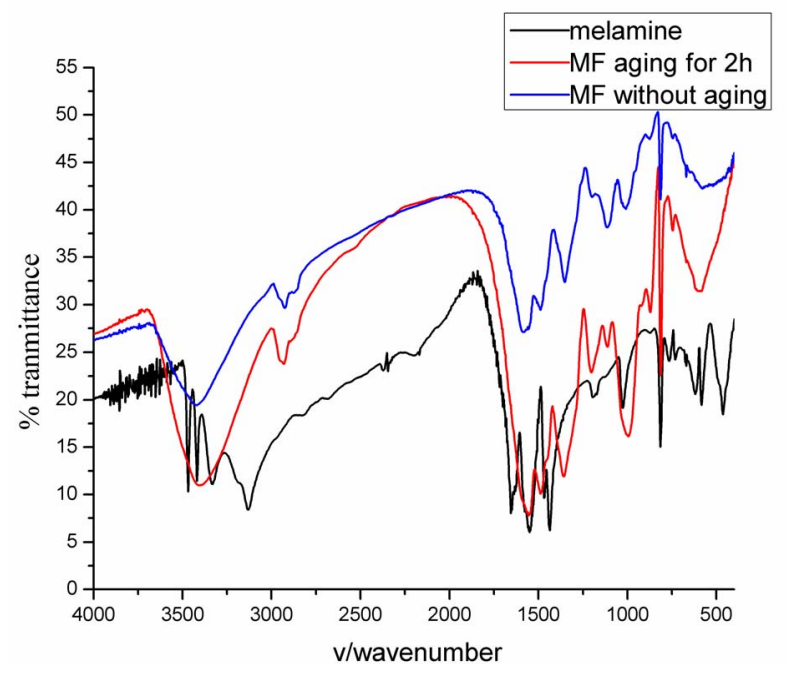

Figure 2. FTIR spectrum of pure Melamine, MF foam without aging and MF foam aging for $2 \mathrm{~h}$ in $120^{\circ} \mathrm{C}$.

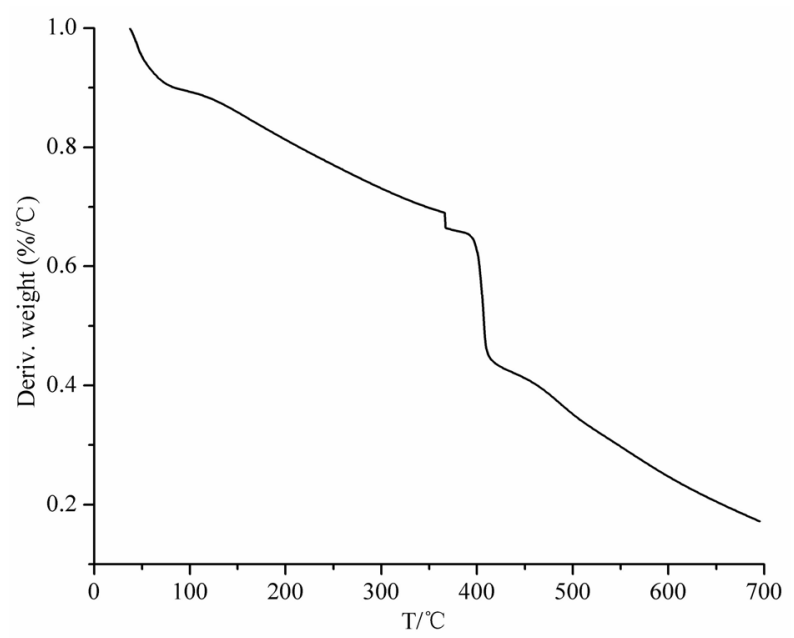

Figure 3. TG curve of MF foam. 
of temperature increasing at $150^{\circ} \mathrm{C}$ the molecule further crosslinked and when temperature reached $180^{\circ} \mathrm{C}$ this reaction finished. When temperature was above $180^{\circ} \mathrm{C}$ there is no obvious endothermic peak which indicates that MF foam is amorphous polymer. Its glass transition temperature $(\mathrm{Tg})$ is higher than 360 ${ }^{\circ} \mathrm{C}$ which attributes to the chemical cross-linking points restrict the movement of molecule chain segment.

In order to examine the constitution of residue, we detected the XRD curve after burning in muffle furnace in $500^{\circ} \mathrm{C}$ for 30 mins. From Figure 5 we can see there is no sharp peak without a wide peak of $2 \theta$ angle at about $25^{\circ}$ which is the characteristic peak of graphite structure and proved that the residue is made up of carbon [12]. The existence of compact carbon or graphite layer can isolate the inner side of foam from oxygen and then extinguish fire at the surface. Thus MF foam can keep stable and integrity even after combustion.

\subsection{Cell Morphology with Different Emulsifiers}

From Figure 6(a) to (e) we can see the foam cell morphology is different with different kinds of emulsifiers as nonionic surfactant, ionic surfactant and co-surfactant as well. Nonionic surfactant H-201 sometimes even works as defoaming agent [13], thus the cell walls seem to be lots of flakes and pile up. The cell diameter is widely distributed and the cell skeletons are not obvious (Figure 6(a)). Tween-80 and OP-10 both belong to nonionic surfactant. It is known that nonionic surfactant will reduce or even loss the foaming ability when temperature is above cloud point [14]. Colin [15] put up a theory that surfactant aqueous solution will separate into two phases in the temperature above cloud point, i.e. a surfactant-rich phase and a surfactant-poor phase which will result in the antifoam action. However, the cell in Figure 6(b) and (c) is relatively uniform when compared to Figrue 6(a) and the cell skeletons are rather clear and much thinner. There are more cell walls in Figure 6(b) compared to Figure 6(c) in amount. These walls are so thin that when compressed by force foam easily appears powder residue and influences its further application. In Figure 6(d) the MF foam is made up of skeletons only. But skeletons are too thin to withstand force and the cell size distributes in large range. Considering that different surfactants works independently and has synergistic effect. When OP-10 and SDBS used together as

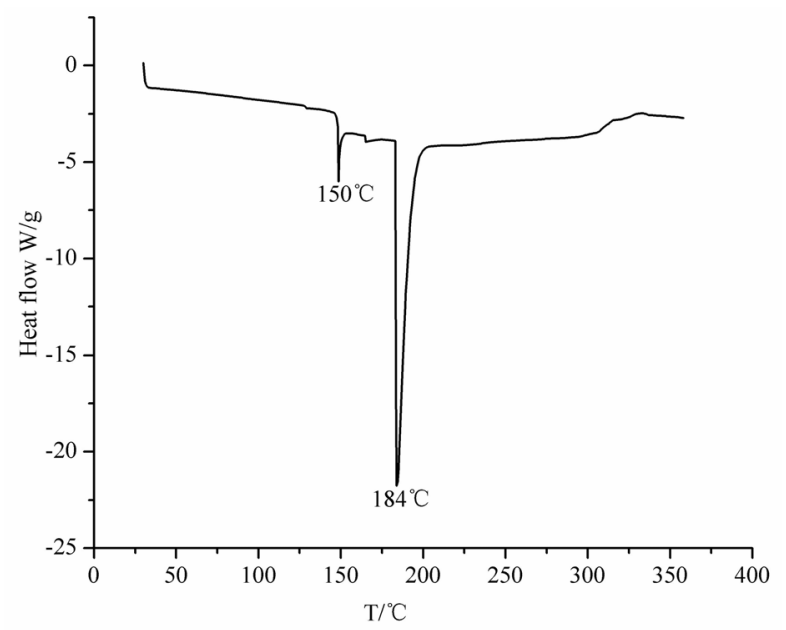

Figure 4. DSC curve of MF foam.

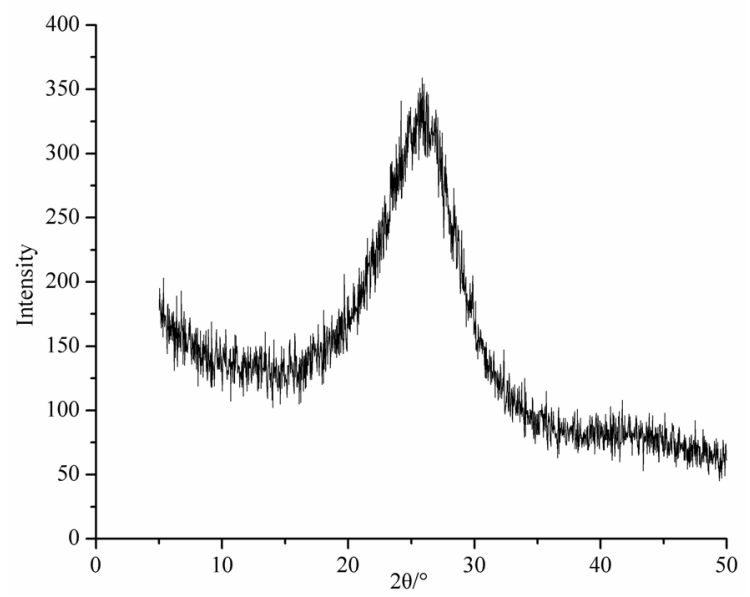

Figure 5. XRD of MF foam after burning for $30 \mathrm{~min}$ in muffle at the temperature of $500^{\circ} \mathrm{C}$.

coemulsifiers the morphology of MF foam appeared to be uniform three-dimensional network structure with cell size between $100 \mu \mathrm{m}$ and $200 \mu \mathrm{m}$. This structure ensured MF foam has good flexibility.
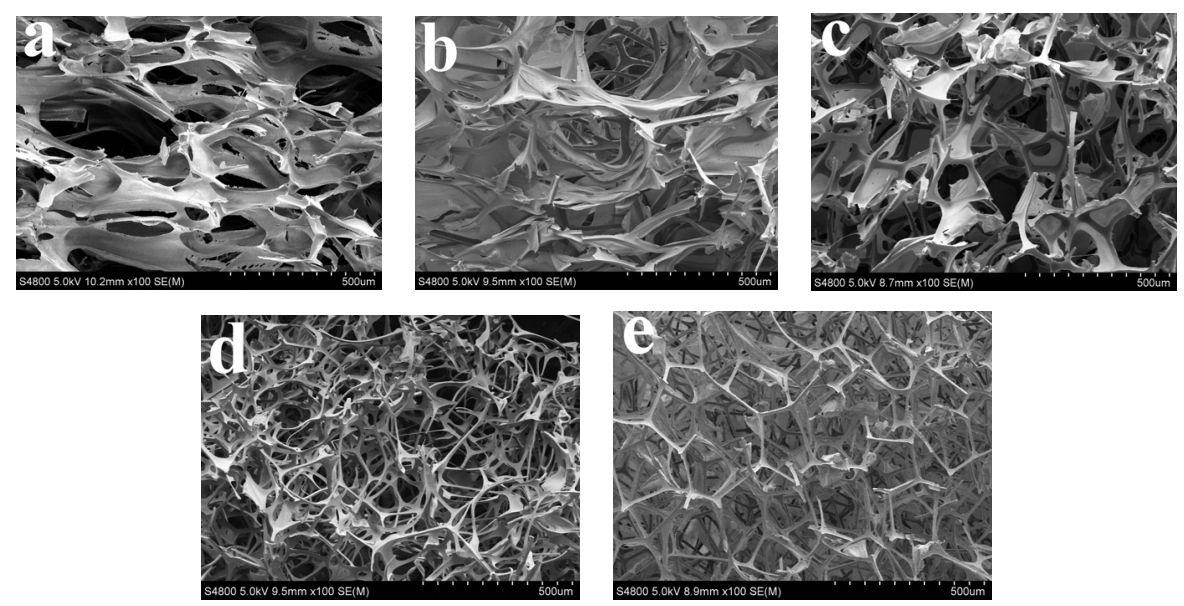

Figure 6. From a to e is the cell morphology of MF foam with emulsifier H-201, Tween-80, OP-10, SDBS, coemulsifiers of OP-10 and SDBS. 


\subsection{Apparent Density and Fire-Retardancy of MF Foam}

Table 1 is the apparent density changes with different emulsifiers and the corresponding values of LOI. From H-201, Tween-80, OP-10, SDBS to OP-10 and SDBS as emulsifiers, the MF foam apparent density and value of LOI respectively reduced which due to the fact that emulsifier affects interfacial tension and then the foam volume and porosity. H-201, Tween- 80 and OP10 are all nonionic emulsifiers but $\mathrm{H}-201$ sometimes worked as defoaming agent which caused the apparent density higher. For the system of MF resin, the ingredients are water-soluble. As a result, the emulsifying capacity of Tween-80 and OP-10 is limited, so the MF foam apparent density is relatively high. SDBS belongs to anionic emulsifier and it is suitable for this watersoluble system. But foaming agent of petroleum ether is oilsoluble, adding OP-10 and SDBS as coemulsifiers can make the emulsifying effect much better. Correspondingly, the MF foam apparent density reduces.

Values of LOI reduced from 36.8 to 32.4 with the apparent density reducing from $14.9 \mathrm{~kg} / \mathrm{cm}^{-3}$ to $5.53 \mathrm{~kg} / \mathrm{cm}^{-3}$. High density MF foam has low porosity and when burned oxygen cannot flow into the inner foam as easily as possible which will restrain combustion. On the contrary, low apparent density has high porosity and oxygen is easier to flow into the inner foam and keep foam burning. As a consequence, the value of LOI is lower.

\subsection{Compression Stress Modulus Changes of MF Foam}

Figure 7 is the compression stress/strain curves of MF foam with different emulsifiers. We can see with apparent density reducing from $14.9 \mathrm{~kg} / \mathrm{cm}^{-3}$ to $5.53 \mathrm{~kg} / \mathrm{cm}^{-3}$ the compressive stress modulus reduces from $0.02 \mathrm{MPa}$ to $0.004 \mathrm{MPa}$ when foams were compressed to $70 \%$. For the MF foam with same apparent density, compressive modulus increases with increasing of deformation and did not achieve maximum. Because deformation caused by stress can make cell skeleton bend and twist. Fyodor [16] deemed that foam structure determined mechanical property with same apparent density. For higher density foam, the L/D of foam skeletons is lower and the contact among foam skeletons becomes closer. When the foam is compressed by stress its modulus is relatively higher and vice versa. The mechanical properties of MF foam with similar structure are consistent with the apparent density.

Table 1. Apparent density changes with different emulsifiers and corresponding values of $\mathrm{LOI}$.

\begin{tabular}{ccc}
\hline emulsifier & Apparent density(kg/cm-3) & LOI \\
\hline H-201 & 14.9 & 36.8 \\
Tween-80 & 14.6 & 36.3 \\
OP-10 & 12.5 & 35.8 \\
SDBS & 9.42 & 34.5 \\
OP-10 and SDBS & 5.53 & 32.4 \\
\hline
\end{tabular}

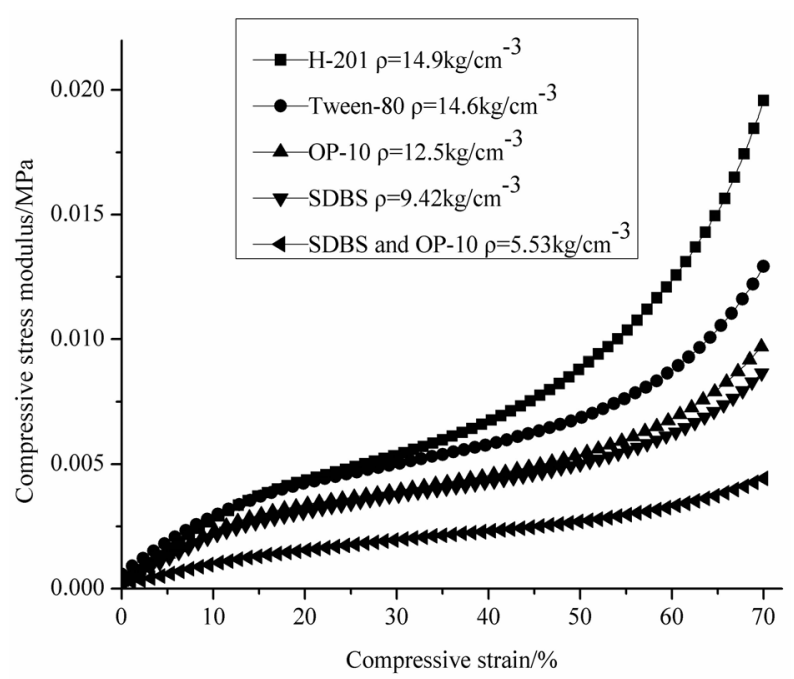

Figure 7. The compressive stress/strain curves.

\section{Conclusion and Outlook}

Through the analysis of emulsifier influenced on MF foam morphology, apparent density and compressive modulus changes as well as fire-retardancy we got that emulsifier is very important to the foaming process. In the actual production SDBS and OP-10 works together as coemulsifiers can provide good emulsifying effect which is suitable for producing flexible MF foam with uniform cell size. The decomposition temperature of MF foam is up to about $395^{\circ} \mathrm{C}$ and the value of LOI can reach 32.4 even when its apparent density is as low as $5.5 \mathrm{~kg} / \mathrm{m}^{-3}$, its fireretardancy is good. Flexible MF foam with similar cell morphology exhibits the similar mechanical property and compression modulus is proportional to the foam apparent density.

In the future research of MF foam there are another two ways to improve its mechanical property. On the one hand, the molecule of MF has long rigid triazinyl and short flexible chain which caused MF foam fragile. So increasing the flexible chain through adding reactive additives such as alkylol amines can improve its flexibility. On the other hand, as the elastic rubber molecules with less cross-linking points if the three-dimensional structure MF molecules reduce the cross-linking degree the flexibility of MF foam will increase. Therefore if the reactive amino of melamine partly be substituted by other groups flexibility can be improved.

\section{Acknowledgements}

This research was supported by NSFC (20805033; 30901199), SRF for ROCS, SEM (2008890-19-9). The authors are grateful for the financial support.

\section{REFERENCES}

[1] Z. S Hang, F. S Jang, F.Y Ju, S.J Ying, F.M Xu. Advances in preparation and application of melamine foam $[\mathrm{J}]$. Thermosetting Resin, 2010, 25(4): 44-52.

[2] D.W Wang, X.X Zhang, D.N Yang, S. Li. Advances in preparation and modification of melamine formaldehyde resin foam [J]. Highlights of Sciencepaper Online, 2012, 5(9): 794-800. 
[3] J Luc, R Ame'lie, D Mickael. Elastic and damping characterizations of acoustical porous materials: Available experimental methods and applications to a melamine foam [J]. Applied Acoustics. 2008, 69: 1129-1140.

[4] K Naoki, U Takayasu, S Yasuhiro, M Hiroshi. Investigation of non-acoustical parameters of compressed melamine foam materials [J]. Applied Acoustics. 2009, 70: 595-604.

[5] R.S Frank, J.M Alex. Aminotriazine-aldehyde foam modified with a primary triol [P]. US3093600, 1963-06-11.

[6] I Yasno, H Shun, O Tatsnya. Melamine resin foam, process for production thereof and melamine/formaldehyde resin condensate [P]. US5436278, 1995-07-25.

[7] J Weise, W Reuther, G Turznik, et al. Melamine resin moldings having increased elasticity [P]. US5084488, 1992-01-28.

[8] I.H Anderson, M Cawley, W Steedman. Melamine Formaldehyde resins I. an examination of some model compound systems [J]. Br. Polym. J., 1969, 1: 24-28.

[9] S Kenji. Condensation of Methylolmelamine [J]. Bulletin of the chemical society of Japan, 1968, 41: 7-17.
[10] F.Q Liu, K.Y Mao, D.H Zhang, X.Y Tang. Structure determination of melamine resins by Fourier transform-infrared spectroscopy [J]. Analytical Chemistry, 1990, 18(5): 409-413.

[11] H Jiang. Study of property of Basofil fiber [J]. Synthetic fiber, 2003, 4: 18-20.

[12] L Zhou. Fire Retardancy of EVA/Multi-walled Carbon Nanotubes Nanocomposites [J]. Chinese Plastics, 2009, 23(7): 23-29.

[13] T Yasusaka, K Mitsuru. Modified silicone oil-in-water emulsion defoaming agent and defoaming method using it [J]. US 005431853A, 1995-11-7.

[14] M.C Per, K Roland, S Per, K.C Hugo. Direct measurement of temperature-dependent interactions between non-ionic surfactant layers [J]. J. Chem. Soc., 1986, 82, 2735-2746.

[15] A.B Colin, D Langevin. Why Do Ethoxylated Nonionic Surfactants Not Foam at High Temperature?[J]. Langmuir, 1997, 13(4): 599-601.

[16] A.S Fyodor. Foamed Polymers. Cellular Structure and Properties [J]. Polymer science. 1983, 51: 155-219. 